\title{
A Comparison of Eggs Per Gram (Epg) from Wet Faecal Smears Stan- dard Method, with Benchtop Flotation with Centrifugal Techniques in Determining the Number of GIN Eggs in Calf Faeces-A Case Study
}

\section{Aphzal Mohammed*, Edward Sampson, Puran Bridgemohan, Angelisah Khan}

The University of Trinidad and Tobago, ECIAF, Caroni North Bank Road, Centeno Arima, West Indies

"Corresponding author: Aphzal Mohammed, Assistant Professor, The University of Trinidad and Tobago, ECIAF, Caroni North Bank Road, Centeno Arima,West Indies; Tel: +868-642 8888; E-mail: aphzal.mohammed@utt.edu.tt

Citation: Mohammed A, Sampson E, Bridgemohan P, Khan A (2017) A Comparison of Eggs Per Gram (Epg) from Wet Faecal Smears Standard Method, with Benchtop Flotation with Centrifugal Techniques in Determining the Number of GIN Eggs in Calf Faeces-A Case Study. Arch Vet Sci Technol, 2017: AVST-121. DOI:10.29011/AVST-121/100021

Received Date: 11 June, 2017; Accepted Date: 17 June, 2017; Published Date: 25 June, 2017

\begin{abstract}
Aim: Although several techniques exist for quantifying GastroIntestinal Nematode eggs (GIN), the method producing the highest egg counts would result in better targeting of parasitic control in livestock.

Materials and Techniques: An experiment was therefore, conducted to determine the best technique in quantifying Gastrointestinal (GIN) helminths eggs in calf faeces by comparing the wet faecal smear, faecal floatation and centrifugation floatation techniques offaeces of a moderately parasitized calfinfested withan initial egg per gram (epg) of nine hundred and fifty (950). Seven (7) techniques were used and observations recorded in triplicate by separate observers. The solutions used for the quantification of were sodium chloride $(\mathrm{NaCl})$, zinc sulphate $(\mathrm{ZnSO} 4)$ and sucrose. The average eggs count from six techniques were tested and findings using descriptive statistics and an ANOVA due to technique are reported.
\end{abstract}

Results: Descriptive statistics showed that centrifugation floatation techniques showed the highest quantification of GIN eggs. Egg counts by centrifugation were highest using floatation solutions sodium chloride followed by sucrose then zinc sulphate. These findings corresponded with high the significant difference $(\mathrm{P}<0.0001)$ found among techniques used.

Conclusion: Therefore, we recommend that centrifugation techniques be used for quantifying GIN eggs in targeting follow up anthelmintic treatment in livestock affected by gastrointestinal parasites.

Keywords: GIN eggs, Solus, Eggs per gram, Faeces, Centrifugation, Floatation

Parasitic infections of livestock pose a serious problem for farmers, and a major obstacle for the development and expansion of the meat industry into a sustainable and profitable market [1]. The direct losses caused by these parasites are usually attributed to acute illness and death, premature slaughter and rejection of some parts at meat inspection. Indirect losses include the diminution of productive potential such as decreased growth rate, weight loss in young growing animals, inconsistent reproductive cycling, late maturity of slaughter stock and poor milk production $[2,3]$. These infections can be either clinical or sub clinical, the latter being the most prevalent and of great economic significance. The economic losses of parasitic infections vary from loss of condition of animals to loss of production.

These GIT parasitic worms belong to the Phyla Platyhelminthes, Nemathelminthes or Nematoda, Acanthocephala and Annelida [4].The Phylum Platyhelminthes contains three classes of worms namely; Turbellaria, Trematoda and Cestoda. All three classes are typically soft-bodied, flattened dorso-ventrally and hermaphroditic. Of major importance however, to grazing livestock are the Nematodes commonly called roundworms, from their appearance in cross-section. The nematode eggs however, differ greatly in size and shape, and the shell is of variable thickness $[5,6]$. Note that, Calves under one year of age in tropical environments are more susceptible to nematodes than older animals [7]. 


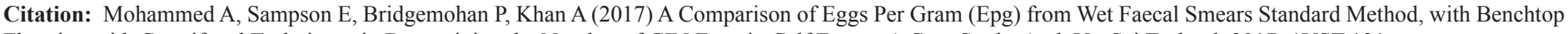
Flotation with Centrifugal Techniques in Determining the Number of GIN Eggs in Calf Faeces-A Case Study. Arch Vet Sci Technol, 2017 : AVST-121.

GIT parasites can be detected by examining faecal samples through various techniques. Faecal egg count or eggs per gram (epg) techniques are used to measure the prevalence and intensity of infections for epidemiological surveys, for recommendation of chemotherapies, and in detecting anthelmintic resistance. There are several other well-established techniques for recovering GIT parasites eggs from faeces including direct smear, sedimentation, floatation and faecal ELISA techniques. The quantitative analysis method for estimating the number of eggs per sample is the McMaster test [8].

The direct faecal smear is used to identify protozoan trophozoite (Giardia, Trichimonads, Amoebae) or other structures that float poorly or are readily distorted by floatation solutions. This method is suitable for a very rapid examination, but will usually fail to detect low-grade infections. This method can be used to separate parasites in all life stages (e.g. eggs, oocysts, sporocysts, cyst and larvae) from other objects and debris based on different densities. The main limitation of direct smears is sample size; with the result that negative smears may not reveal light to moderate parasite levels [9,2]. Floatation solutions are made by adding a measured amount of salt or sugar to a specific amount of water to produce a solution of desired Specific Gravity (SG), using a hydrometer. Floatation techniques can vary from the simplest to the complex, which relies on the differences in the Specific Gravity (SG), of the $\operatorname{egg}(\mathrm{s})$, faecal debris, and floatation solution. Floatation techniques using sucrose media is used for detecting (whipworms), Taenia species (Tapeworms), Toxocara species (roundworms), Eucoleus (Capillaria) species (roundworms), and Isospora (coccidian) species $[8,2]$. The main limitation of floatation is their inability to float organism whose diagnostic stage has a specific gravity higher than of the floatation medium and can unintentionally omit up to $50 \%$ undetected eggs [9], most commonly being the heavy ova of trematodes.

This purpose of this study was to quantify of GIN eggs from a moderately infested calf faecal sample, by comparing faecal floatation and centrifugation techniques using sodium chloride, zinc sulphate and sucrose solutions

\section{Materials and Techniques}

\section{Samplings}

Faecal samples were taken using rectal sleeves from seven (7) calves at the Centeno Livestock Station. From the seven (7) calves examined, the faecal samples showed by the McMaster counting method that four (4) were negative for GIN eggs, two (2) were lightly infected (both samples contained 250 eggs per gram) and one (1) was heavily infected with nine hundred and fifty (950) eggs per gram. The sample with nine hundred and fifty (950) eggs per gram was selected as the test sample for the study.

\section{Methodology}

The sample was thoroughly mixed with a wooden palette to achieve a homogenous egg distribution. The McMaster method quantifying GIN eggs was carried out using seven techniques namely, the direct faecal smear, including the faecal floatation and centrifugation techniques with sodium chloride, zinc sulphate and sucrose solutions, respectively. Five (5) grams of fresh faeces was weighed initially and $30 \mathrm{mls}$ of the chosen floatation solution (sodium chloride, zinc sulphate or sucrose) were combined to attain a specific gravity between 1.18 and 1.20 using a hydrometer. Immediately afterwards the chambers of the McMaster slide were filled with the mixture using a Pasteur pipette or syringe. If visible air bubbles were detected, the fluid was removed and refilled. The idea was to focus on the slide was on the top layer, which contained the very small (pinhead) air bubbles. At this layer, the lines of the grid also became in focus. Eggs were then counted including oocysts present in each lane of both chambers. The number of parasite eggs per gram, were added from the counts for both chambers. The results of both chambers were counted as the eggs in $0.3 \mathrm{ml}$, which was $1 / 200$ th of the total volume of $60 \mathrm{ml}$. The number of eggswere then multiplied by 200 . However, since the experiment began with $4 \mathrm{~g}$ of faeces, the resulting count was divided by 4 to yield eggs per gram of faeces. Multiplying by 200 and dividing by 4 was equivalent to multiplying the number of eggs counted by 50 .

Faecal floatation was based on the principle that when a faecal sample was placed in a sugar or salt solution, parasites (and other objects) less dense than the floatation solution moved to the top of the solution and parasites denser than the solution will eventually settle to the bottom. The faeces were properly emulsified with a tongue depressor. The solution was then strained thru a tea strainer with mixing being done to squeeze out all the fluids.

For the centrifugation techniques-centrifugation was carried out for 10 minutes at $3000 \mathrm{rpm}$ and tube was left undisturbed with its cover-slip for 5 minutes [11]. The speed of the centrifuge was then gradually increased to the target $3000 \mathrm{rpm}$. When the rotor speed was increased gradually to the target speed, the centrifuge bucket moved slowly to a horizontal position and the cover-slip will have stayed in stable position. The cover-slip was removed from the sample tube one deliberate upward motion, and placed on the microscope for observation. One side of the cover-slip was placed on the slide first and lowered gradually at an angle onto the glass slide as described previously to prevent entrapped air bubbles. An analysis of variance due to technique was carried out using Minitab 19, 2013.

\section{Results and Discussion}

(Table 1) shows the Mean, Standard Error of the Mean (SEM), Standard Deviation (SD), Maximum, Median, and Minimum eggs counts of the seven detection techniques studied. 


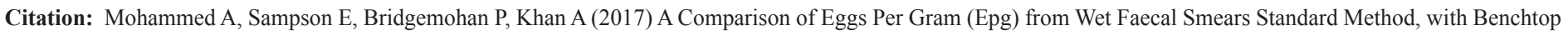
Flotation with Centrifugal Techniques in Determining the Number of GIN Eggs in Calf Faeces-A Case Study. Arch Vet Sci Technol, 2017 : AVST-121.

\begin{tabular}{|c|c|c|c|c|c|c|c|c|}
\hline Variable & Method & N & Mean & SEM & SD & Minimum & Median & Maximum \\
\hline Egg Counts & 1 & 6 & 3.667 & 0.558 & 1.366 & 2.000 & 3.500 & 130.0 \\
\hline & 2 & 6 & 95.5 & 11.1 & 27.2 & 67.0 & 88.5 & 42.00 \\
\hline & 3 & 6 & 23.33 & 7.41 & 18.15 & 5.00 & 22.50 & 104.0 \\
\hline & 4 & 6 & 50.5 & 11.9 & 29.1 & 20.0 & 45.5 & 1979 \\
\hline & 5 & 6 & 1349 & 194 & 476 & 658 & 1430 & 966.0 \\
\hline & 6 & 6 & 748.7 & 82.6 & 202.4 & 452.0 & 742.5 & 2063 \\
\hline & 7 & 6 & 1260 & 279 & 683 & 371 & 1392 & \\
\hline
\end{tabular}

Table 1: Mean, Standard Error of the Mean (SEM), Standard Deviation (SD), Maximum, Median, and Minimum eggs counts of the seven GIN quantification

Methods:1- Faecal wet smear; 2 -Feacal flotation Sodium Chloride; 3-Faecal flotation Zinc Sulphate; 3-Faecal Flotation Sucrose5 -Centrifugation flotation Sodium Chloride; 6-Centrifugation; CentrifugationZinc Sulphate; 7-Centrifugation Flotation Sucrose

(Table 2) shows the analysis of variance pertaining to technique used for quantifying GIN eggs.

\begin{tabular}{|c|c|c|c|c|c|}
\hline Source & DF & SS & MS & F & P \\
\hline Reps & 5 & 614572 & 122914 & 1.20 & 0.331 \\
\hline Method & 6 & 13191448 & 2198575 & 21.53 & 0.000 \\
\hline Error & 30 & 3064102 & 102137 & & \\
\hline Total & 41 & 16870123 & & & \\
\hline
\end{tabular}

Table 2: Two-way ANOVA: Egg counts versus reps, trt

Methods:1-Faecal wet smear; 2-Feacal flotation Sodium Chloride; 3-Faecal flotation Zinc Sulphate; 3-Faecal Flotation Sucrose;5Centrifugation Flotation Sodium Chloride; 6-Centrifugation; CentrifugationZinc Sulphate; 7-Centrifugation Flotation Sucrose

(Table 3) - Analysis of Variance for sqrt, using Adjusted SS for Tests

\begin{tabular}{|c|c|c|c|c|c|c|}
\hline Source & DF & Seq SS & Adj SS & $\begin{array}{c}\text { Adj } \\
\text { MS }\end{array}$ & F & P \\
\hline & & & & & & \\
\hline Reps & 5 & 112.82 & 112.82 & 22.56 & 0.84 & 0.532 \\
\hline Method & 6 & 7838.45 & 7838.45 & 1306.41 & 48.61 & 0.000 \\
\hline Error & 30 & 806.18 & 806.18 & 26.87 & & \\
\hline Total & 41 & 8757.45 & & & & \\
\hline
\end{tabular}

Table 3: Analysis of Variance for sqrt, using Adjusted SS for Tests

Methods; 1- Faecal wet smear; 2 -Feacal flotation Sodium Chloride; 3-Faecal flotation Zinc Sulphate; 3-Faecal Flotation Sucrose5 -Centrifugation flotation Sodium Chloride; 6-Centrifugation; Centrifugation Zinc Sulphate; 7-Centrifugation Flotation Sucrose

Mean, and median eggs counts showed that centrifugation floatation techniques resulted in the highest quantification of GIN eggs. Egg counts by centrifugation were highest using floatation solutions sodium chloride followed by sucrose then zinc sulphate (Table 1). These findings corresponded with high significant differences found $(\mathrm{P}<0.0001)$ among techniques used (Table 2). Higher GIN Eggs retrieval by Zinc sulphate has been found in preschool children in Irac. Higher egg counts for the centrifugation Zinc Sulphate method compared with the benchtop method have been reported in other studies $[10,11,12]$.

Therefore, we recommendcentrifugation techniques be used for quantifying GIN eggs in targeting follow up anthelmintic treatment in livestock affected by gastrointestinal parasites.

\section{Acknowledgements}

We wish to thank laboratory technician Ms. Valerie Khan for preparing various floatationsolutions andassisting us in the visual detection ofGIN eggs on the Macmaster slides.

\section{Reference}

1. Palbergen C, Nijsse R (2013) The mini- FLOTAC, a comparison with the centrifugal sedimentation/flotation, McMaster and the passive flotation technique for coproscopical examination of dog feces Research report Utrecht University, Faculty of Veterinary Medicine

2. Pfukenyi DM, Mukaratirwa S, Willingham AL, Monrad J (2007) 'Epidemiological studies of parasitic gastrointestinal nematodes, cestodes and coccidia infections in cattle in the highveld and lowveld communal grazing areas of Zimbabwe', OnderstepoortJournal of Veterinary Research 74: 129-142.

3. Bowan DD (2003) Georgis Parasitology for Veterinarians (8 $8^{\text {th }}$ edition) Saunders, United States of America.

4. Boomker J, Horak IG, Macivor KM, De F (1989) Helminth parasites of grysbok, common duikers, and Angora and Boer goats in the Valley Bushveld in the Eastern Cape Province. Onderstepoort Journal of Veterinary Research 56: 165-172.

5. Boomker J, Horak IG, Ramsay KA (1994) Helminth and arthropod parasites of indigenous goats in the northern Transvaal, Onderstepoort journal of Veterinary Research 61: 13-20.

6. Fikru R, Teshale S, Reta D, Yosef K, Fikru R (2016) Epidemiology of Gastrointestinal Parasites of Ruminants in Western Oromia, Ethiopia J Appl Res Vet Med 1: 51-57. 


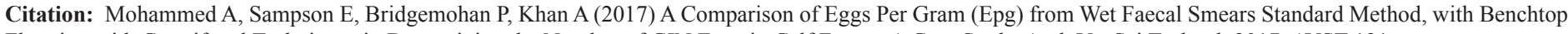
Flotation with Centrifugal Techniques in Determining the Number of GIN Eggs in Calf Faeces-A Case Study. Arch Vet Sci Technol, 2017 : AVST-121.

7. Byron BL, Jamie BM (2006) Optimize intestinal parasite detection with centrifugal faecal floatation.

8. David ED, Lindquist WD (1982) Determination of the specific gravity of certain helminth eggs using sucrose density gradient centrifugation. Journal of Parasitology 68: 916-919.

9. Dryden MW, Payne PA, Ridley R (2005) Comparison of common faecal flotation technique for the recovery of parasite eggs and oocysts. Veterinary Therapeutics 6: 15-28.

10. Dryden MW, Payne PA (2010) Diagnostics / NAVC Clinician's Brief 13-126.

11. Gates, Nolan (2013)Comparison of Passive Fecal Flotation Run by Veterinary Students to Zinc-Sulfate Centrifugation Flotation Run in a Diagnostic Parasitology Laboratory Journal of Parasitology 95: 1213-1214.

12. Santare'm VA, Magoti LP, Sichieri TD (2009) Influence of variables on centrifuge-flotation technique for recovery of Toxocara canis eggs from soil. Rev Inst Med trop Sao Paulo 51: 163-167.

13. Soulsby EJL, London, Bailliere, Tindall, Cassell, et al. (1980) Arthropods \& Protozoa of domesticated animals $6^{\text {th }}$ edn. of monning's veterinary helminthology \& entomology). O'Grady MR, Slocombe JOD: An investigation of variables in a fecal floatation technique. Can J Comp Med 44: 148-154.
14. Payne PA, Dryden MW (2003) Accurate evaluation of fecal samples critical to patient. DVM Best Practices Mar: 8-11.

15. Urquhart GM, Armour, Duncan JL, Dunn AM, Jennings FW (1996) Veterinary Parasitology $2^{\text {nd }}$ edn. University of Glasgow Scotland.

16. Christie J, Schwan EV, Bodenstein LL, Sommerville JEM, van der Merwe LL (2011) Thesensitivity of direct faecal examination, direct faecal flotation, modified centrifugal faecalflotation and centrifugal sedimentation/flotation in the diagnosis of canine spirocercosis.J. South Afric. Vet, Assoc82: 71-75.

17. O'Grady MR, Slocombe JOD (1980) An Investigation of Variables in a Fecal Flotation Technique. Can. J. comp. Med. 44: 148-154.

18. Christopher KC, Bernadette VS (2008) Comparison of methods to detect gastrointestinal parasites in llamas and alpacas. JAVMA 5: 733741.

19. Katagiri S, Oliveira-Sequeira TC (2010) Comparison of three concentration methods for the recovery of canine intestinal parasites from stool samples. International Journal of Current Microbiology and Applied Sciences 126: 2014-216. 